Published in final edited form as:

Neuropediatrics. 2003 June ; 34(5): 225-233.

\title{
Functional magnetic resonance imaging in pediatrics
}

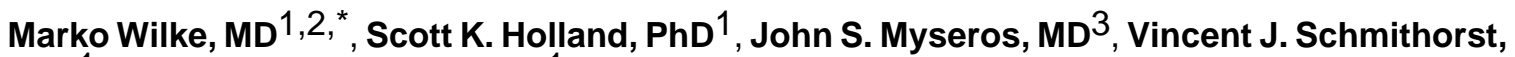 \\ PhD $^{1}$, and William S. Ball Jr., MD ${ }^{1}$ \\ ${ }^{1}$ Imaging Research Center and ${ }^{2}$ Divisions of Psychiatry and ${ }^{3}$ Neurosurgery Cincinnati Children's Hospital \\ Medical Center, 3333 Burnet Avenue, ML 5031, Cincinnati, OH 45229
}

\begin{abstract}
Functional magnetic resonance imaging (fMRI) allows non-invasive assessment of human brain function in vivo by detecting blood flow differences. In this review, we want to illustrate the background and different aspects of performing functional magnetic resonance imaging (fMRI) in the pediatric age group. An overview over current and future applications of fMRI will be given, and typical problems, pitfalls, and benefits of doing fMRI in a pediatric age group are discussed. We conclude that fMRI can successfully be applied in children and holds great promise for both research and clinical purposes.
\end{abstract}

\section{Introduction}

Functional magnetic resonance imaging (fMRI) is a rapidly evolving application allowing visualization neuronal activation in vivo. Since functional MRI was first described only 10 years ago [43], rapid progress has been made in this field, and the technique is now put to widespread use for clinical and research purposes in adult subjects [14,28]. However, although a number of previous studies have included pediatric patients [15,18,23,24,25,54,55], pediatric fMRI-applications are literally still in their infancy.

In this paper, we will briefly review the basics of fMRI and address the specific problems of conducting functional MRI in the pediatric age group. We will then outline the current research and clinical applications this exciting technique has in pediatrics and will close with an outlook on possible future developments.

\section{Functional MRI: background \\ Origin of the fMRI-signal}

Functional MRI relies on two basic assumptions: first, neuronal activation induces an increase in glucose metabolism, and second, this increased demand is met by an increase in local cerebral blood flow [11,37]. This localized increase in cerebral blood is measured using different MRtechniques that are sensitive to small changes in the magnetic field that accompany these blood flow changes. The most abundantly used technique is known as "blood oxygenation level dependant" (BOLD) contrast and uses blood itself as an internal contrast medium [13]. BOLD imaging exploits tiny magnetization differences between oxygenated and deoxygenated hemoglobin (Figure 1) [11,13,14]: since neuronal activation is followed by an increase in blood flow exceeding the actual demand, more oxygenated hemoglobin appears in the venous capillaries within the brain parenchyma. This shifts the relation between oxygenated and

* Corresponding authors present address: Dept. of Pediatric Neurology and Developmental Medicine, Children's Hospital, University of Tübingen, Hoppe-Seyler-Str. 3, 72076 Tübingen, Germany, Phone: +49 707129 - 83416, Fax: +49 707129 - 5473, e-mail: Marko.Wilke@med.uni-tuebingen.de. 
deoxygenated hemoglobin and thus (due to the different magnetic properties of the two forms) induces minute local distortions in the magnetic field (on the order of 1-4\% [11]). Because capillary density in gray matter is much higher in gray matter, the effect in gray matter dominates the overall signal.

Figure 1 also illustrates two other characteristics of the BOLD-signal as detectable by BOLDfMRI: first, neuronal activation is actually detected slightly "downstream", i.e., in the draining venous vessels, and second, this (among other factors) introduces a certain "lag" from the onset of activation until the detection of measurable BOLD-signal (typically about 4-6 seconds $[11,35])$. It should also be kept in mind that the exact mechanism by which the increase in blood flow is elicited (and thus the exact neural correlate of the BOLD-signal) is still the subject of ongoing research [11,37], with recent progress combining different methodologies [34,35].

\section{Image acquisition- and processing-issues}

The magnetic field differences induced by the BOLD-effect are detectable using MRsequences sensitive to changes in susceptibility (or T2*-weighted) contrast [11]. Functional MRI is typically done using fast imaging techniques, with echo-planar imaging (EPI) being the most widely used method [27,30]. EPI has two main features making it highly suitable for fMRI: first, each image slice is acquired very rapidly (typically in about $100 \mathrm{msec}$ ). This makes the resulting single image robust against motion-corruption, and motion between images can be corrected (to a certain extent) using dedicated correction algorithms. Secondly, EPI gives excellent T2*-contrast, making it very sensitive to the BOLD-effect. Unfortunately, EPI is also vulnerable to typical and significant image artifacts, including geometrical distortion and Nyquist ghosts [30] (Figure 2). Although higher-field MR-scanners have the distinct advantage of a much better signal-to-noise ratio, benefiting fMRI greatly [33], the artifacts also become more severe. Therefore, since these artifacts prohibit a one-to-one correspondence of structural and functional imaging data, they must be adequately corrected before a functional study can be overlaid on the high-resolution, non-distorted structural study (as, for example, in Figure 3 or 8$)[30,50]$.

Another potential pitfall inherent in BOLD-fMRI is the fact that, as mentioned above, the signal arises predominantly in venous capillaries draining an activated brain region. A potential ramification of this is mis-location of activation "downstream" from the correct site of activity, leading to spurious signals in the resulting images without concomitant neuronal activation $[27,32]$. This issue will be discussed in more depth below in the "clinical fMRI"-section.

Functional MRI is very sensitive to motion, and thus motion correction is a necessary step in the post-processing of functional MRI-data, even more so in children [57]. Visual assessment of the raw data (in the form of a movie loop) may provide some clues as to the extent of the motion. However, motion correction should routinely be done in all of studies, for which a number of algorithms are available now [4]. This has the advantage of not only ensuring consistent data processing but also allows objective determination of the overall amount of adjustment made by the algorithm. This quantitative information can then be taken into account when judging the results, and a threshold can be set for rejecting data due to motion. Another important asset in dealing with the problem of motion-compromised studies is the ability to do online data-reconstruction and -processing. A first assessment of the scan-quality while the child is still in the scanner allows for a timely intervention, e.g. the repetition and/or addition of a functional study. Ultimately, if all attempts to conduct a functional study in an awake child fail, at least passive tasks can also be employed in sleeping or sedated children [3], although changes in physiological parameters may significantly influence the expected results, especially in very young children [38]. 
Regarding further post-processing of images, it is necessary to keep in mind that normative reference data most often was obtained from adult subjects, and using such data may introduce a systematic bias into the resulting images [59]. However, at the current resolution used in fMRI, the differences seem to be tolerable [8]. Generally, developmental differences need to be kept in mind when analyzing pediatric fMRI-images [56].

\section{Paradigms for fMRI}

An fMRI-paradigm ideally will lead to the activation of brain regions of interest while not involving other regions [2]. This can be achieved by carefully matching active and rest states in as many aspects as possible in order to "isolate" the function of interest. Again, working with a pediatric population calls for special considerations regarding appropriateness for the age group studied [57]. Practical examples of simple fMRI-tasks will be given below when specific clinical/research areas are discussed.

The fact that the magnetic field changes induced by neuronal activation are very small currently results in two important limitations of fMRI-tasks: first, classical fMRI is only able to detect differences between states (usually termed "rest" and "active"), since only a difference in neuronal activation (and thus, blood flow) is detectable. Second, large numbers of images must be obtained for each state and are then statistically compared with each other to assess intensity changes correlating with the task (see pixel intensity course in Figure 3, right). However, both limitations will become less relevant with the further development of advanced post-processing approaches [39] and the more abundant use of high-field MR-scanners (3 Tesla and above), since signal-to-noise increases with field strength and allows for a more flexible design [33].

\section{Special considerations for pediatric subjects}

Subject preparation is key in doing successful (f)MRI-studies in children. The inability of a young child to lie still in the scanner is one of the major hindrances to effective functional imaging in this age group [57]. A high degree of flexibility regarding subject handling, preparation and scheduling is necessary in order to account for this major obstacle. If fMRI is to be routinely employed in the pediatric age group, the staff of the participating MRI-center must be flexible and willing to make a commitment to the additional resources needed to tailor the procedures to the individual child. This is exemplified in the case of a 5-year-old boy, who, despite the best efforts of an experienced team, was not able to participate in an fMRI-study when it was first scheduled. He was rescheduled for a few days later, and his parents were given written instructions and an audio-CD that allowed them to practice the tasks with the child at home. He was able to participate effectively in the second scan, with good results (see Figure 3).

In the authors' experience a good preparation and a calm and child-centered atmosphere are more decisive than the amount of time allotted for a given exam. Therefore, a procedure has been set in place in our center where the children are met by an fMRI-team member prior to the scan and are taken to the MRI-suite. Here, children are shown a short video of an 7-yearold girl completing a routine fMRI-study on one of our scanners. Whatever questions they (or the parents) might have are answered, informed consent is obtained, and they are taken to the scanner where they are introduced to the equipment and given demonstrations of the magnetic field ("magnet tricks"). The tasks are explained and practiced outside the scanner (with the same equipment used inside). In the case of an add-on exam (following a routine clinical MRI), children are also contacted and prepared before the scan starts.

During positioning, great care is taken to ensure maximal comfort. For the scan, MRcompatible headphones and video goggles are used over which children can watch visually presented stimuli or a movie (during non-functional parts of the exam). The setup is shown in 
Figure 4 for a 6-year old child. Such equipment is invaluable in reducing anxiety and ensuring compliance (and thus, reducing motion) [9,57]. Children are addressed and talked to frequently between the scans and are constantly monitored via a closed-circuit video system. Parents are allowed to stay with the child if they wish to do so and if no contraindications exist.

With this routine, a more than $50 \%$ success rate even in 5-year-old (healthy) children is achieved; older children do significantly better, and overall, girls have a higher rate of successfully completed exams than boys [9]. With the highly motivated neurosurgery patients, we experience an even better rate of successful studies, while a much lower rate of successful studies must be expected in neurologically or psychiatrically impaired subjects.

\section{Current research applications}

Functional MRI is an exciting tool in neuroscience since it literally allows us to "watch the brain thinking". The absence of harmful radiation not only allows studying children in general, but also makes exams in healthy volunteers and repeated exams possible: an important difference from using data from "apparently normal" subjects who were investigated for clinical reasons $[46,57]$. Over the last decade, fMRI has been employed to address a multitude of open questions in neuroscience; here, we will focus on three issues that have received widespread attention and are of special significance for pediatric neurology: language organization and development, brain plasticity, and neurobehavioral disorders.

\section{Language organization and development}

Language is among the most-studied brain functions since for the first time, knowledge about this central human capability can be deduced not (indirectly) from lesion models, but (directly) from healthy subjects in vivo $[6,24,57]$. These investigations have provided a number of new insights into how language is processed in the brain, including the broader role of what were classically thought to be language-specific areas for other functions, the greater contribution of right-hemispheric regions, and increases of language lateralization with age (Figure 5) [6, $24,60]$.

Language development is considered a sensitive parameter of overall normal development in children [24], especially during the first years [44]. Language functions continue to develop rapidly over the first two decades of life, and knowledge of normal development is necessary to allow for the identification of pathological patterns in disorders involving language problems. At present, such normative data is still lacking, but as it becomes available, it will allow pathological patterns and developmental abnormalities to be identified early on. This is especially important considering the huge variability in parameters derived from such studies (see variability of individual results in Figure 5), underlining the necessity to include sufficient numbers of subjects in pediatric fMRI-studies [57] A number of different tasks can be used to examine language functions. One such "child-friendly" paradigm is the widely used verb generation task: a noun is presented every five seconds, and the child is asked to "generate action-words that go with that word". Thirty second-blocks of cued verb-generation are interleaved with blocks of cued bilateral finger-tapping (sequential tapping of all fingers to the thumb) [24]. The finger tapping serves both as a distraction from generating further verbs and allows for the routine delineation of the hand region in the primary motor cortex. Another task readily applicable in a pediatric fMRI-session is a stories-listening task: children are asked to listen to short stories ( 30 seconds each), alternated with 30 second-blocks of listening to simple tones of the same bandwidth as the voice reading the stories. Therefore, acoustic processing is present in both blocks (and is therefore canceled out), while language processing only occurs in the active condition and is thus detectable. To ensure/increase attention, children are told beforehand that they will be questioned about the stories after the study is complete; this data 
is also used to judge compliance. In our experience, this task is doable even by children as young as 5 years [9].

The (active) verb generation task on average results in the detection of a left-lateralized language network, consistent with a semantic decision-making process involving the dominant hemisphere $[6,24]$. The (passive) story-task, weighted towards syntactic processing, results in a more bilateral activation, mostly involving receptive language areas (see Figure 6) [17]. While overall patterns at first sight seem similar in adults and children, important differences exist: language lateralization increases with age [24,60], a number of areas show age-related changes in activation [51], and there is first evidence that the BOLD-signal itself could change with age [50], even after the first years [38]. Developing a pattern of normal language development and then integrating abnormal variations into it will be one of the major challenges of the near future.

\section{Brain plasticity}

The ability of children's brains to recover from insults is unparalleled: children have long-since been known to recover better from traumatic insults like stroke or hemispherectomy, especially if they occur within the first year of life [10,41]. This high level of plasticity is remarkable in many ways, and the most obvious implications of elucidating the mechanisms involved is a better understanding of the neural basis for rehabilitation. This is of course of great interest not only in children, but especially in adult patients, where strokes are among the leading causes of disability and where recovery is more often incomplete [10]. Functional MR-imaging seems to be among the most promising tools in further defining the processes taking place during recovery from injury. For example, fMRI permits longitudinal studies during the course of rehabilitation, allowing direct visualization of the in vivo- recovery of brain functions. Most studies to date have investigated patients remote from the incidence, i.e. investigate the endresult of brain plasticity $[7,25,55]$. One recent study investigated a patient before and after epilepsy surgery [22], demonstrating the potential of longitudinal studies. Another important approach will be the combination of different methodologies like fMRI and transcranial magnet stimulation (TMS) [45], as applied recently in a study on motor reorganization in children with cerebral palsy [54]. As yet, however, the data does not allow painting a clear picture on what mechanisms predominantly contribute to the unique plasticity of the young brain.

\section{Neurobehavioral disorders}

The term "neurobehavioral disorders" refers to a diverse group of enigmatic conditions, some of which are very common (like attention-deficit/hyperactivity disorder [ADHD] or pediatric mood disorders), others are very rare (like childhood-onset schizophrenia). While only until recently regarded as the sole domain of psychiatrists and psychologists, imaging studies have helped to move these disorders into the spotlight of neuroscience research [16,21]. By demonstrating neurobiological deficits in distinct brain regions, the foundations can be laid for a better understanding and thus, better treatment.

In the case of ADHD, fMRI-studies have provided interesting information about activation differences between normal controls and unmedicated [48] and medicated subjects with ADHD [58]. The latter study elegantly investigated the effect of medication, demonstrating opposite effects on activation in the basal ganglia [58] and thus illustrating the potential of such investigations. ADHD, however, also points towards the limitations of fMRI-studies in childhood neurobehavioral disorders: the strong comorbidity with other neurological disorders (including learning disabilities, conduct disorder, and mood and tic disorders) and the special sensitivity of fMRI to motion artifacts make research on this disorder exceedingly difficult [21]. 
Pediatric mood disorders, while common and having a severe psychosocial impact [42], have not yet been studied using fMRI. The same is true for childhood-onset schizophrenia, although there is agreement that such studies will be important in further developing hypothesis on the origin of these disorders, especially with regard to their putative neurodevelopmental component [36]. It seems that the occurrence of such disorders "out of the ordinary", i.e. earlier in life than usual, provides a special opportunity to study their neuroanatomical substrate. However, much work remains to be done in this area before any given theory is supported by actual data.

\section{Current clinical applications}

\section{Clinical fMRI}

Clinical fMRI refers to the application of fMRI in patients prior to undergoing neurosurgical intervention. The superior temporal and spatial resolution of BOLD-fMRI, combined with the lack of ionizing radiation, make it the preferable choice over methods like PET, which have also been used [28,31]. While not (yet) approved for reimbursement by most medical insurance carriers, pre-surgical evaluation is the application where fMRI is closest to becoming part of a clinical routine. There are currently two major goals that are actually or potentially addressable using this approach: the delineation of eloquent cortex near a space-occupying lesion [15,28] and the determination of the "dominant hemisphere" for language [12,23]. Many more applications are currently developed that, e.g., try to directly identify seizure focuses using EEG-correlated fMRI [29] or are aimed at assessing medial temporal lobe structures prior to epilepsy surgery [20]. For the purpose of this overview, we will focus on the two main applications mentioned above.

Defining eloquent cortex-Even in normal volunteers, classical anatomical landmarks do not always overlap with the functional area attributed to them, a problem worsened by the presence of a space-occupying lesion [61]. Therefore, the visualization of eloquent cortical regions near a brain lesion in order to minimize the potential of post-operative neurological sequelae has gained widespread attention $[15,28,31,47,61]$. One of the major advantages of using fMRI instead of direct intra-operative mapping by cortical stimulation [28] is its noninvasiveness and the fact that it can be done as part of a routine clinical MRI. Further advantages are its wide availability, lack of ionizing radiation, high spatial and temporal resolution and the direct coregistration with high-resolution anatomical data $[15,28]$.

It is important to keep in mind that there is no one "pre-surgical fMRI", but that every exam needs to be tailored to the individual patient, based on as much clinical and radiological information as possible. Therefore, close and informed cooperation between neurologist/ oncologist, neurosurgeon and radiologist is of paramount importance. For example, in the classical case of a patient with a perirolandic lesion [28], the exact location of the lesion, clinical symptoms, and planned neurosurgical procedure all are important in order to define the fMRIparadigms to be used. Time constraints also need to be considered since an exam cannot be expected to include more than $2-4$ paradigms. In young or strongly neurologically impaired children, studies may have to be even more limited.

The potential benefit of doing pre-interventional MRI is illustrated by the following case: a 14-year-old boy was studied for a lesion in his pre-central gyrus (Figure 7, left). A combined finger-tapping/verb-generation paradigm was used as described above. In this case, activation could be seen both anterior and posterior to the lesion (Figure 7, right), prompting a reevaluation of the planned neurosurgical approach. Following removal of the lesion through a small corticectomy (histology verified neurocysticercosis), the patient suffered no postoperative deficits. 
The relevance of the potential for false-positive activation in draining vessels mentioned above must be stressed for pre-interventional fMRI: although good agreement of fMRI-maps and cortical stimulation could be shown in low-grade gliomas [47], it should be kept in mind that even in the absence of overt pathological vessels, the localizing accuracy especially of BOLDfMRI may be altered close to brain tumors [26] due to a loss of vascular auto-regulation. Higher field-strength, spin-echo techniques, advanced post-processing approaches, and highresolution fMRI may all help in minimizing this confound $[27,40]$. The effect is shown in Figure 8 in a child performing a passive listening-task as part of a pre-surgical evaluation: a strong negative activation was found close to the lesion (Figure 8, left). One approach to aid in the decision on the origin of a given signal change is the direct comparison of functional activation maps with (MR-) angiographic images [49] or with contrast-enhanced images [15, 32]. The latter modality is independent of blood flow velocity, which might lead to a more sensitive detection of (pathological) vessels (as shown in Figure 8, right). Pending further systematic studies on this issue, it is our opinion that either MR-angiographic or contrastenhanced images should be used to evaluate possibly spurious "functional" activation in close proximity to a space-occupying lesion, especially in suspected high-grade or vascular lesions [49].

Despite these drawbacks, clinically indicated fMRI to delineate eloquent cortex is feasible and beneficial in selected pediatric neurosurgery patients, and a more widespread use of this application is to be expected.

Determination of the dominant hemisphere-One point of special interest has been the question of hemispheric lateralization of language functions, especially in comparison with the intra-carotid amytal test (Wada-test) [5,12,23,53]. Functional lateralization is most often expressed as a lateralization index, weighting the activation in both hemispheres against each other [12]. Greater specificity can be achieved by only including language-related areas [24]; more regionally specific assessment of activation may further improve the predictive value [53]. A number of tasks are able to detect a left-lateralized language network, albeit to a lesser degree in children than in adults [24,60] (Figure 5,6). Results from such tasks have been shown to have a high correlation with results obtained with the invasive Wada-test regarding hemispheric dominance [5,12], also in children [23]. Recent results obtained using a readingtask [19] have led to the conclusion that the time to replace the Wada-test is "almost there" [1], pending further investigations on the ability of fMRI to predict post-interventional language or memory impairment. To this end, first results seem to indicate that specially designed memory paradigms in combination with high-resolution fMRI are able to lateralize memory functions in patients with temporal lobe epilepsy (Figure 9 [56]). Therefore, the combination of greater spatial specificity and additional information to be gained from a combined MRI/fMRI-exam will, in our opinion, lead to the replacement of the invasive Wadatest in the medium term.

\section{Conclusions and Outlook}

Functional BOLD-MRI in the pediatric age group requires a multi-disciplinary team effort, combining strong expertise in the techniques and an environment that does justice to the special needs of children. Pediatricians are especially called for to play an important part in implementing and advancing this technique in the pediatric age group.

A number of exciting research questions have already been addressed using fMRI in children, but many more open questions remain. Many of these are only addressable in children, where a number of neurological parameters are different from what is observable in adults.

Understanding the normal development of functions seems key in addressing a wide range of 
neurological disorders in both children and adults, and these unique opportunities should not be missed.

Some clinical applications of fMRI are about ready to be used as part of a routine procedure, but many practical questions are still unsolved. In particular, complex acquisition and postprocessing issues still demand strong local expertise and background in order to not only successfully acquire, but also critically judge fMRI-results. However, constant technical and theoretical progress will continue to move the ideal of a robust and routine evaluation of pediatric neurosurgical patients closer to reality.

We conclude that, with the feasibility, practicality and benefit of functional MRI for both research and clinical applications demonstrated, its routine use in pediatric patients and subjects should be further explored and endorsed.

\section{Acknowledgements}

We would like to thank the team members whose vast experience and expert knowledge so invaluably contributes to the high success rate of this unit: W. A. Bommer, J. Ret, R. S. Dunn, and K. J. O'Brien. We would also like to thank Dr. Dobyns for soliciting this review. This work was supported in part by a grant from the U.S. National Institute of Child Health and Human Development, RO1-HD38578-03.

\section{References}

1. Abou-Khalil B, Schlaggar BL. Is it time to replace the Wada test ? Neurology 2002;59:160-161. [PubMed: 12136050]

2. Aguirre GK, D’Esposito M: Experimental Designs for Brain fMRI. In: Moonen CTW, Bandettini PA (eds). Functional MRI. Berlin Heidelberg New York, Springer-Verlag, 2000: 369-380

3. Altman NR, Bernal B. Brain activation in sedated children: auditory and visual functional MR imaging. Radiology 2001;221:56-63. [PubMed: 11568321]

4. Ardekani BA, Bachman AH, Helpern JA. A quantitative comparison of motion detection algorithms in fMRI. Magn Reson Imaging 2001;19:959-963. [PubMed: 11595367]

5. Binder JR, Swanson SJ, Hammeke TA, Morris GL, Mueller WM, Fischer M, et al. Determination of language dominance using functional MRI: a comparison with the Wada test. Neurology 1996;46:978984. [PubMed: 8780076]

6. Bookheimer S. Functional MRI of language: New Approaches to Understanding the Cortical Organization of Semantic Processing. Annu Rev Neurosci 2002;25:151-188. [PubMed: 12052907]

7. Briellmann RS, Abbott DF, Caflisch U, Archer JS, Jackson GD. Brain reorganisation in cerebral palsy: a high-field functional MRI study. Neuropediatrics 2002;33:162-165. [PubMed: 12200747]

8. Burgund ED, Kang HC, Kelly JE, Buckner RL, Snyder AZ, Petersen SE, et al. The Feasibility of a Common Stereotactic Space for Children and Adults in fMRI Studies of Development. NeuroImage 2002;17:184-200. [PubMed: 12482076]

9. Byars AW, Holland SK, Strawsburg RH, Schmithorst VJ, Dunn RS, Ball WS, Jr.: Practical Aspects of Conducting Large-Scale fMRI Studies in Children. J Child Neurol (in press)

10. Chen R, Cohen LG, Hallett M. Nervous system reorganization following injury. Neuroscience 2002;111:761-773. [PubMed: 12031403]

11. Chen W, Ogawa S: Principles of BOLD functional MRI. In Moonen CTW, Bandettini PA (Eds.): Functional MRI. Springer-Verlag, Berlin Heidelberg New York, 103-113, 2000

12. Desmond JE, Sum JM, Wagner AD, Demb JB, Shear PK, Glover GH, et al. Functional MRI measurement of language lateralization in Wada-tested patients. Brain 1995;118:1411-1419. [PubMed: 8595473]

13. Detre JA, Wang J. Technical aspects and utility of fMRI using BOLD and ASL. Clin Neurophysiol 2002;113:621-634. [PubMed: 11976042]

14. Di Salle F, Formisano E, Linden DE, Goebel R, Bonavita S, Pepino A, et al. Exploring brain function with magnetic resonance imaging. Eur J Radiol 1999;30:84-94. [PubMed: 10401589] 
15. Dymarkowski S, Sunaert S, Van Oostende S, Van Hecke P, Wilms G, Demaerel P, et al. Functional MRI of the brain: localisation of eloquent cortex in focal brain lesion therapy. Eur Radiol 1998;8:1573-1580. [PubMed: 9866764]

16. Frank Y, Pavlakis SG. Brain imaging in neurobehavioral disorders. Pediatr Neurol 2001;25:278-287. [PubMed: 11704396]

17. Friederici AD, Meyer M, von Cramon DY. Auditory language comprehension: an event-related fMRI study on the processing of syntactic and lexical information. Brain Lang 2000;75:289-300. [PubMed: 11386224]

18. Gaillard WD, Hertz-Pannier L, Mott SH, Barnett AS, LeBihan D, Theodore WH. Functional anatomy of cognitive development: fMRI of verbal fluency in children and adults. Neurology 2000;54:180185. [PubMed: 10636145]

19. Gaillard WD, Balsamo L, Xu B, Grandin CB, Braniecki SH, Papero PH, et al. Language dominance in partial epilepsy patients identified with an fMRI reading task. Neurology 2002;59:256-265. [PubMed: 12136067]

20. Golby AJ, Poldrack RA, Illes J, Chen D, Desmond JE, Gabrieli JD. Memory lateralization in medial temporal lobe epilepsy assessed by functional MRI. Epilepsia 2002;43:855-863. [PubMed: 12181004]

21. Hale TS, Hariri AR, McCracken JT. Attention-deficit/hyperactivity disorder: perspectives from neuroimaging. Ment Retard Dev Disabil Res Rev 2000;6:214-219. [PubMed: 10982499]

22. Hertz-Pannier L, Chiron C, Jambaque I, Renaux-Kieffer V, Van de Moortele PF, Delalande O, et al. Late plasticity for language in a child's non-dominant hemisphere: a pre- and post-surgery fMRI study. Brain 2002;125:361-372. [PubMed: 11844736]

23. Hertz-Pannier L, Gaillard WD, Mott SH, Cuenod CA, Bookheimer SY, Weinstein S, et al. Noninvasive assessment of language dominance in children and adolescents with functional MRI: a preliminary study. Neurology 1997;48:1003-1012. [PubMed: 9109891]

24. Holland SK, Plante E, Byars AW, Strawsburg RH, Schmithorst VJ, Ball WS Jr. Normal fMRI Brain Activation Patterns in Children Performing a Verb Generation Task. Neuroimage 2001;14:837-843. [PubMed: 11554802]

25. Holloway V, Gadian DG, Vargha-Khadem F, Porter DA, Boyd SG, Connelly A. The reorganization of sensorimotor function in children after hemispherectomy. A functional MRI and somatosensory evoked potential study. Brain 2000;123:2432-2444. [PubMed: 11099446]

26. Holodny AI, Schulder M, Liu WC, Wolko J, Maldjian JA, Kalnin AJ. The effect of brain tumors on BOLD functional MR imaging activation in the adjacent motor cortex: implications for image-guided neurosurgery. AJNR Am J Neuroradiol 2000;21:1415-1422. [PubMed: 11003273]

27. Howseman AM, Bowtell RW. Functional magnetic resonance imaging: imaging techniques and contrast mechanisms. Philos Trans R Soc Lond B Biol Sci 1999;354:1179-1194. [PubMed: 10466145]

28. Jack CR, Lee CC, Ward HA, Riederer SJ. The role of functional MRI in planning perirolandic surgery. In: Moonen CTW, Bandettini PA (eds). Functional MRI. Berlin Heidelberg New York, SpringerVerlag, 2000: 539-550

29. Jager L, Werhahn KJ, Hoffmann A, Berthold S, Scholz V, Weber J, et al. Focal epileptiform activity in the brain: detection with spike-related functional MR imaging - preliminary results. Radiology 2002;223:860-869. [PubMed: 12034960]

30. Jezzard P, Clare S. Sources of distortion in functional MRI data. Hum Brain Mapp 1999;8:80-85. [PubMed: 10524596]

31. Kaplan AM, Bandy DJ, Manwaring KH, Chen K, Lawson MA, Moss SD, et al. Functional brain mapping using positron emission tomography scanning in preoperative neurosurgical planning for pediatric brain tumors. J Neurosurg 1999;91:797-803. [PubMed: 10541237]

32. Krings T, Erberich SG, Roessler F, Reul J, Thron A. MR blood oxygenation level-dependent signal differences in parenchymal and large draining vessels: implications for functional MR imaging. AJNR Am J Neuroradiol 1999;20:1907-1914. [PubMed: 10588117]

33. Kruger G, Kastrup A, Glover GH. Neuroimaging at 1.5 T and 3.0 T: Comparison of oxygenationsensitive magnetic resonance imaging. Magn Reson Med 2001;45:595-604. [PubMed: 11283987] 
34. Lauritzen M. Relationship of spikes, synaptic activity, and local changes of cerebral blood flow. J Cereb Blood Flow Metab 2001;21:1367-1383. [PubMed: 11740198]

35. Logothetis NK. The neural basis of the blood-oxygen-level-dependent functional magnetic resonance imaging signal. Philos Trans R Soc Lond B Biol Sci 2002;357:1003-1037. [PubMed: 12217171]

36. Luna B, Sweeney JA. Studies of brain and cognitive maturation through childhood and adolescence: a strategy for testing neurodevelopmental hypotheses. Schizophr Bull 2001;27:443-455. [PubMed: 11596846]

37. Magistretti PJ, Pellerin L. Cellular mechanisms of brain energy metabolism and their relevance to functional brain imaging. Phil Trans R Soc Lond B 1999;354:1155-1163. [PubMed: 10466143]

38. Martin E, Joeri P, Loenneker T, Ekatodramis D, Vitacco D, Hennig J, et al. Visual processing in infants and children studied using functional MRI. Pediatr Res 1999;46:135-140. [PubMed: 10447104]

39. McKeown MJ, Sejnowski TJ. Independent component analysis of fMRI data: examining the assumptions. Hum Brain Mapp 1998;6:368-372. [PubMed: 9788074]

40. Menon RS. Postacquisition suppression of large-vessel BOLD signals in high-resolution fMRI. Magn Reson Med 2002;47:1-9. [PubMed: 11754436]

41. Moses P, Stiles J. The lesion methodology: contrasting views from adult and child studies. Dev Psychobiol 2002;40:266-277. [PubMed: 11891638]

42. National institutes of Mental Health. National Institute of Mental Health research roundtable on prepubertal bipolar disorder. J Am Acad Child Adolesc Psychiatry 2000;40:871-878.

43. Ogawa S, Tank DW, Menon R, Ellermann JM, Kim SG, Merkle H, et al. Intrinsic signal changes accompanying sensory stimulation: functional brain mapping with magnetic resonance imaging. Proc Natl Acad Sci USA 1992;89:5951-5955. [PubMed: 1631079]

44. Oller DK, Eilers RE, Neal AR, Cobo-Lewis AB. Late onset canonical babbling: a possible early marker of abnormal development. Am J Ment Retard 1998;103:249-263. [PubMed: 9833656]

45. Rijntjes M, Weiller C. Recovery of motor and language abilities after stroke: the contribution of functional imaging. Prog Neurobiol 2002;66:109-122. [PubMed: 11900884]

46. Rivkin MJ. Developmental neuroimaging of children using magnetic resonance techniques. Ment Retard Dev Disabil Res Rev 2000;6:68-80. [PubMed: 10899799]

47. Roux FE, Boulanouar K, Ranjeva JP, Tremoulet M, Henry P, Manelfe C, et al. Usefulness of motor functional MRI correlated to cortical mapping in Rolandic low-grade astrocytomas. Acta Neurochir (Wien) 1999;141:71-79. [PubMed: 10071689]

48. Rubia K, Overmeyer S, Taylor E, Brammer M, Williams SC, Simmons A, et al. Hypofrontality in attention deficit hyperactivity disorder during higher-order motor control: a study with functional MRI. Am J Psychiatry 1999;156:891-896. [PubMed: 10360128]

49. Schad LR. Improved target volume characterization in stereotactic treatment planning of brain lesions by using high-resolution BOLD MR-venography. NMR Biomed 2001;14:478-483. [PubMed: 11746940]

50. Schapiro MB, Holland SK, Schmithorst VJ, Wilke M, Weber Byars A, Strawsburg R. Functional magnetic resonance imaging (fMRI) brain activation increases with age in children performing a finger tapping task. Ann Neurol 2002;52:S135.

51. Schlaggar BL, Brown TT, Lugar HM, Visscher KM, Miezin FM, Petersen SE. Functional neuroanatomical differences between adults and school-age children in the processing of single words. Science 2002;296:1476-1479. [PubMed: 12029136]

52. Schmithorst VJ, Dardzinski BJ, Holland SK. Simultaneous correction of ghost and geometric distortion artifacts in EPI using a multiecho reference scan. IEEE Trans Med Imaging 2001;20:535539. [PubMed: 11437113]

53. Spreer J, Arnold S, Quiske A, Wohlfarth R, Ziyeh S, Altenmuller D, et al. Determination of hemisphere dominance for language: comparison of frontal and temporal fMRI activation with intracarotid amytal testing. Neuroradiology 2002;44:467-474. [PubMed: 12070719]

54. Staudt M, Grodd W, Gerloff C, Erb M, Stitz J, Krägeloh-Mann I. Two types of ipsilateral reorganization in congenital hemiparesis: A TMS and fMRI study. Brain 2002;125:2222-2237. [PubMed: 12244080] 
55. Staudt M, Lidzba K, Grodd W, Wildgruber D, Erb M, Krägeloh-Mann I. Right-hemispheric organization of language following early left-sided brain lesions: functional MRI topography. Neuroimage 2002;16:954-967. [PubMed: 12202083]

56. Szaflarski JP, Holland SK, Shear PK, Schmithorst VJ, Strakowski SM, et al. Using different fMRI language and memory tasks in healthy adults at 3T. Epilepsia 2002;43(Suppl 8):55.

57. Thomas KM, Casey BJ. Functional MRI in pediatrics. In: Moonen CTW, Bandettini PA (eds). Functional MRI. Berlin Heidelberg New York, Springer-Verlag, 2000: 513-524

58. Vaidya CJ, Austin G, Kirkorian G, Ridlehuber HW, Desmond JE, Glover GH, et al. Selective effects of methylphenidate in attention deficit hyperactivity disorder: a functional magnetic resonance study. Proc Natl Acad Sci USA 1998;95:14494-14499. [PubMed: 9826728]

59. Wilke M, Schmithorst VJ, Holland SK. Assessment of spatial normalization of whole-brain magnetic resonance images in children. Hum Brain Mapp 2002;17:48-60. [PubMed: 12203688]

60. Wilke M, Schmithorst VJ, Weber AM, Strawsburg RH, Holland SK. Changes in the language lateralization index with age as detected by functional MRI in normal children. Neuropediatrics 2002;33:A4.

61. Yetkin FZ, Papke RA, Mark LP, Daniels DL, Mueller WM, Haughton VM. Location of the sensorimotor cortex: functional and conventional MR compared. AJNR Am J Neuroradiol 1995;16:2109-2113. [PubMed: 8585502] 


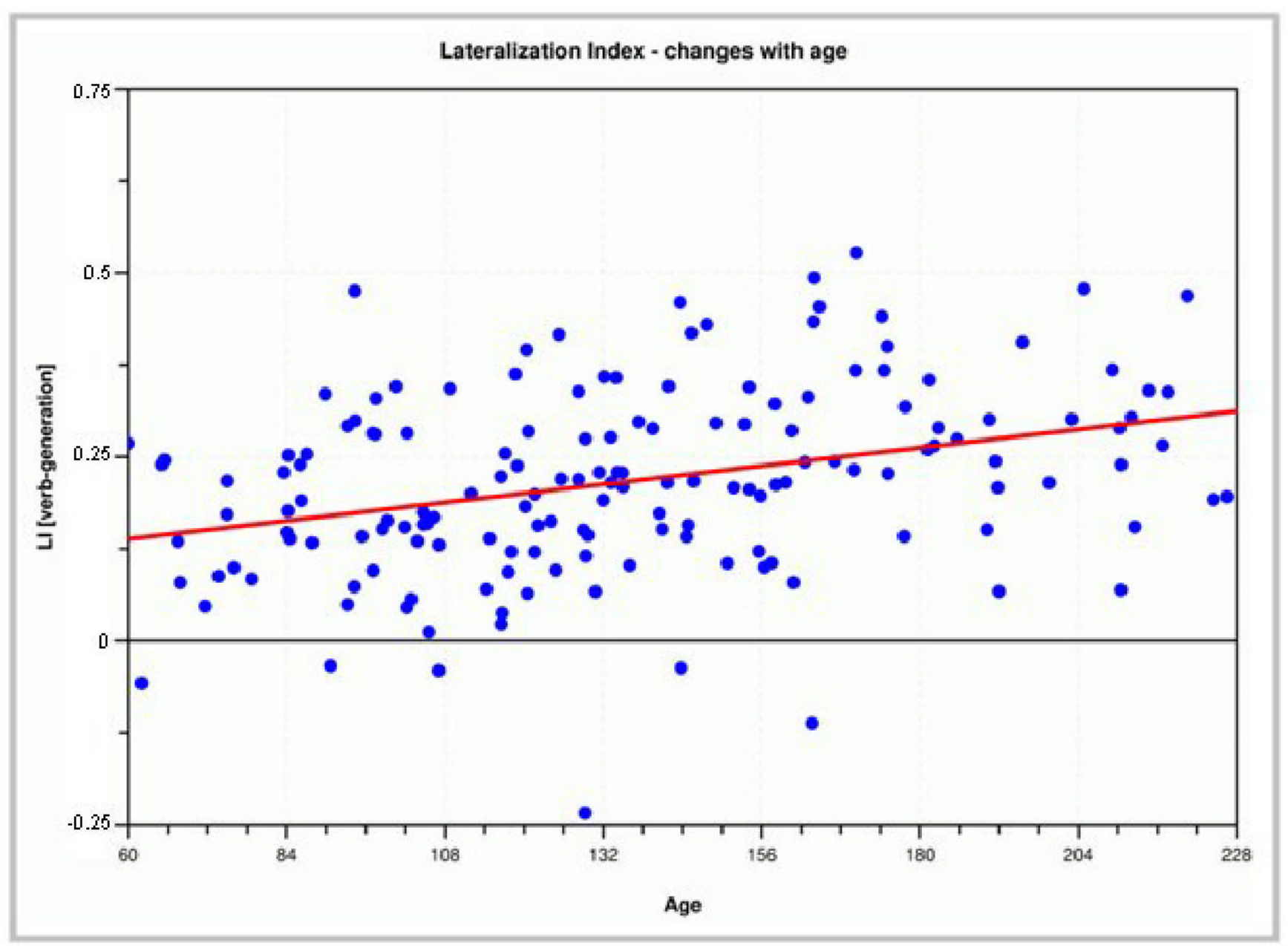

Figure 1.

Illustration of the BOLD-effect: during rest (top), equilibrium exists between oxygenated hemoglobin (left) and de-oxygenated hemoglobin (right). Activation (bottom) induces an influx of oxygenated hemoglobin exceeding demand, thus shifting the equilibrium in draining vessels. See text for details. 


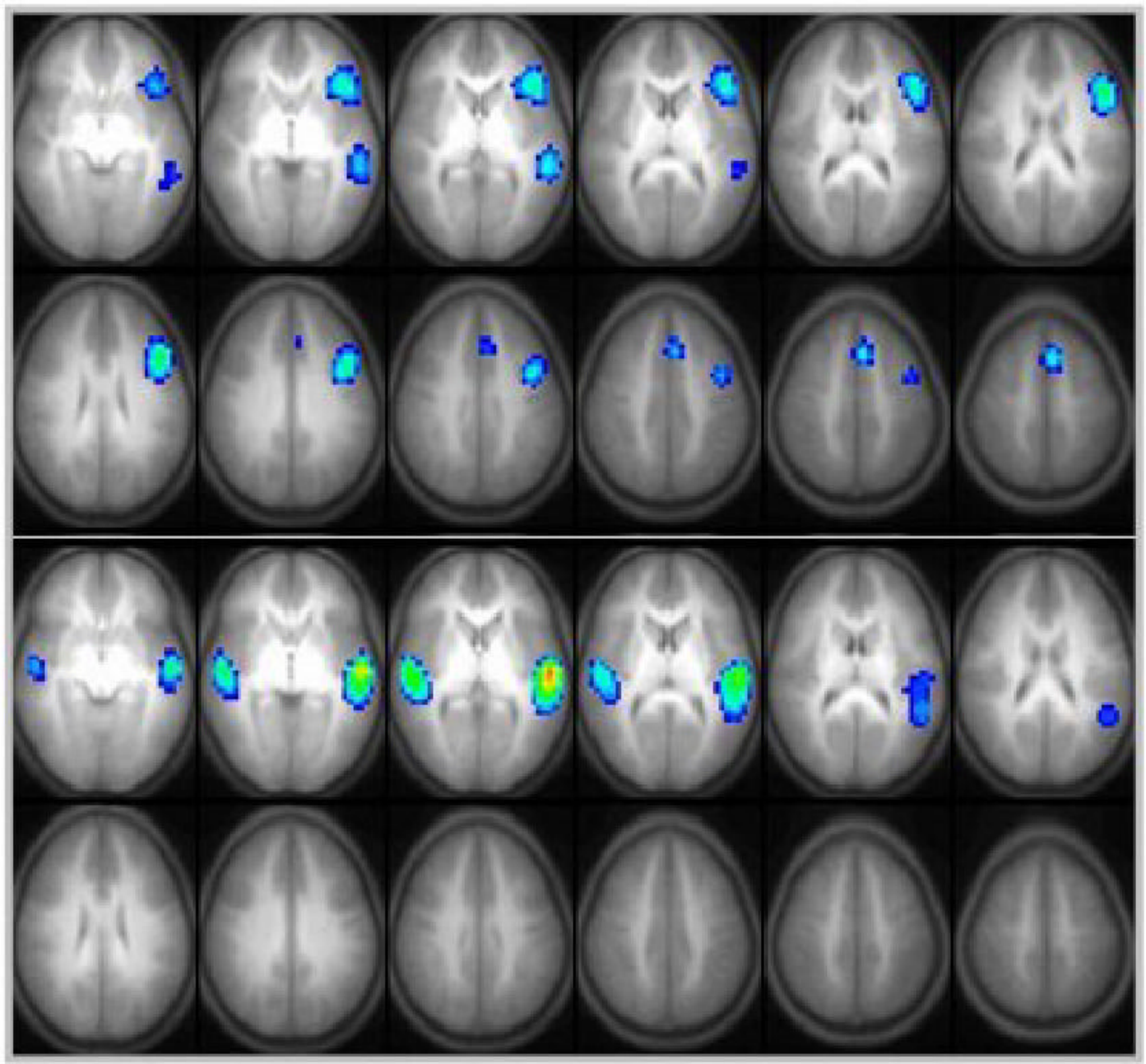

Figure 2.

Demonstration of EPI-artifacts: top left: conventional (undistorted) gradient-echo image; top right: raw EPI-image (note distortion of image and "ghosting" in front and back); bottom left: distorted image after correction of Nyquist-ghosts; bottom right: final, geometry- and ghostcorrected EPI-image. 


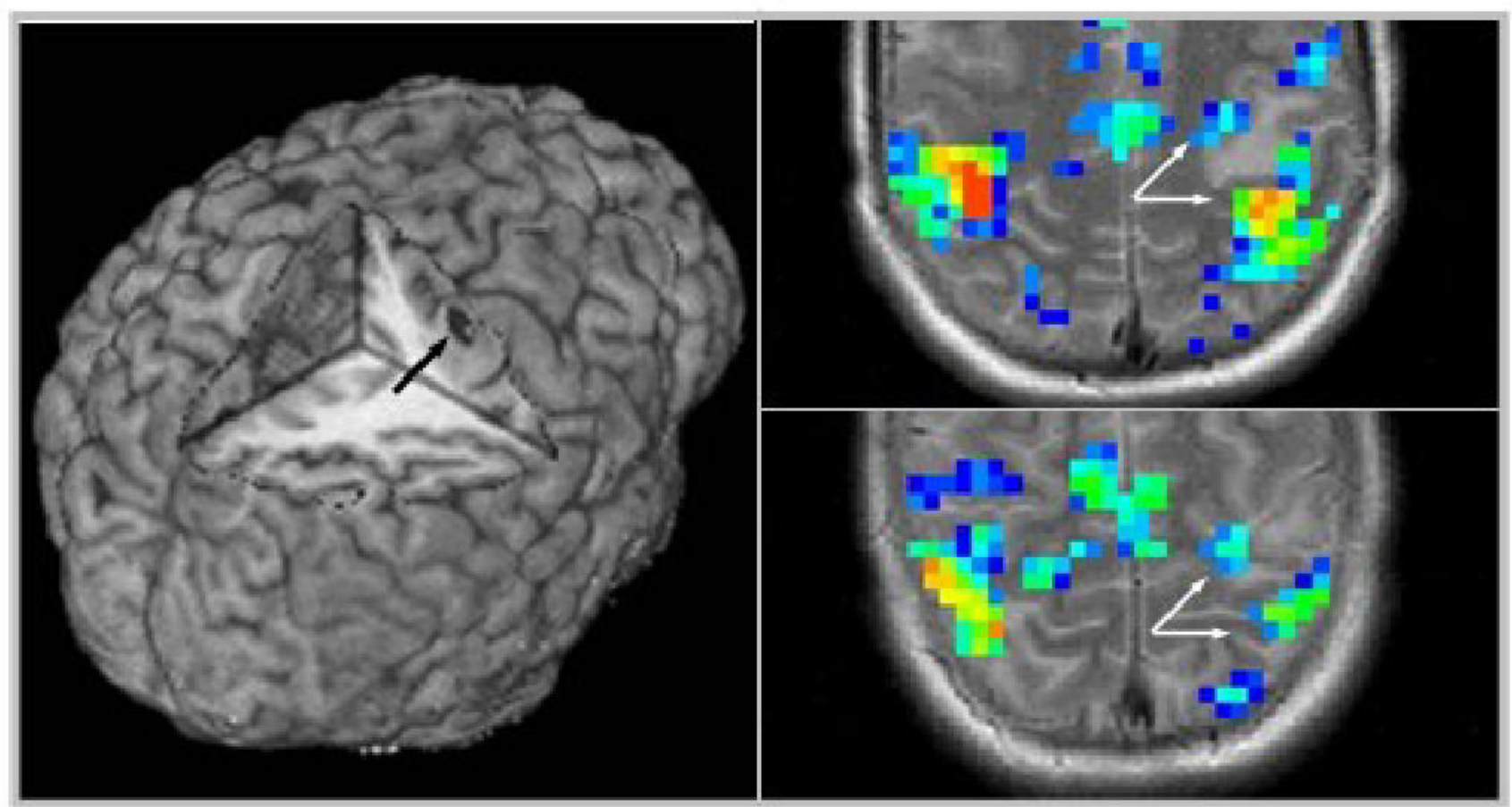

Figure 3.

Brain activation while listening to a story in a 5-year-old boy, overlaid on the corresponding anatomical study (left); corresponding pixel-intensity time course (right). Note the overall only $\sim 2 \%$ signal change. 


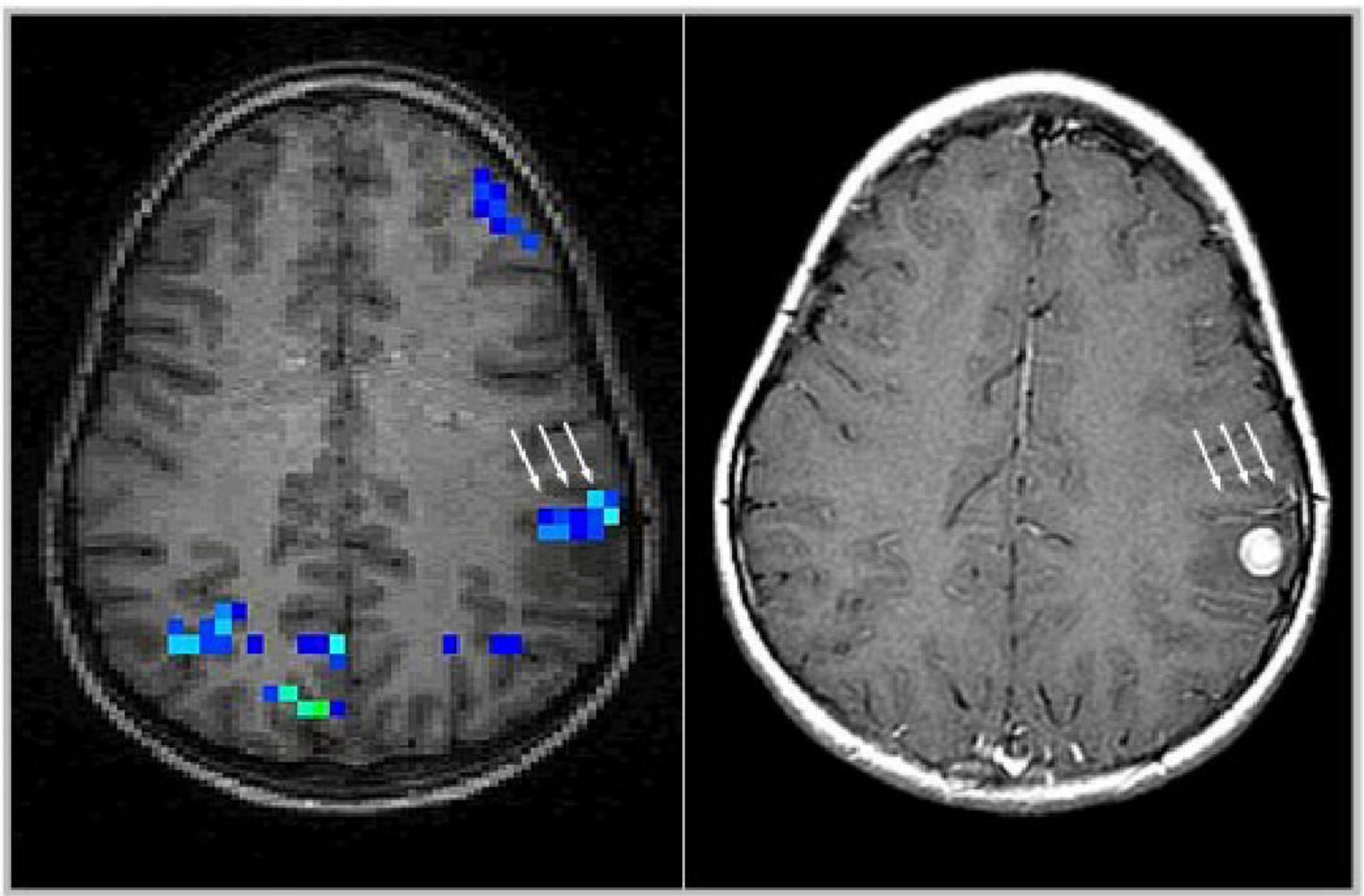

Figure 4.

Audiovisual MRI-setup, demonstrated with a 6-year-old girl; note MR-compatible headphones and video goggles. 


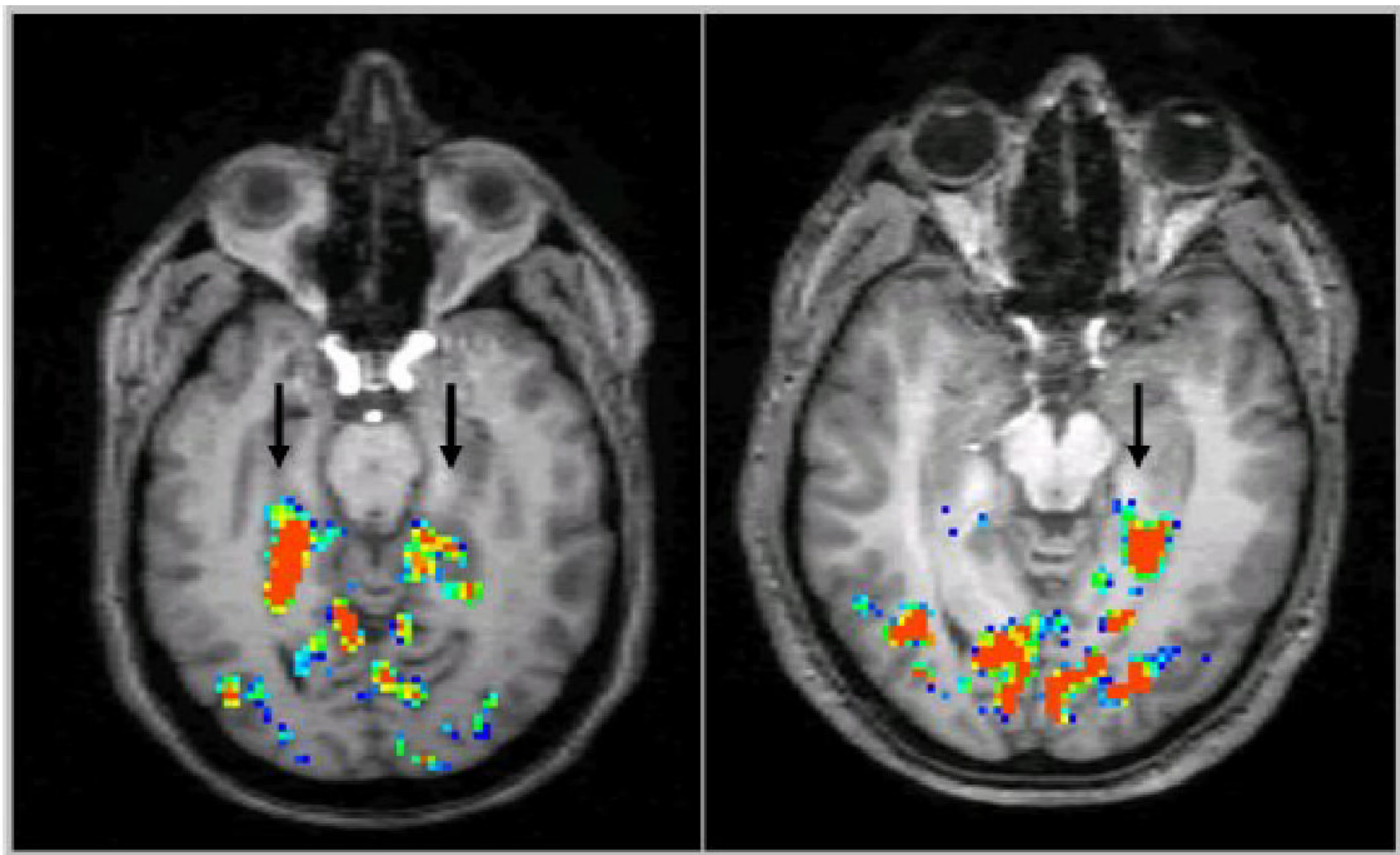

Figure 5.

Language lateralization index as detected by a verb generation paradigm: lateralization significantly increases with age $\left(\mathrm{p}<1^{-5}, \mathrm{n}=158\right)$. 


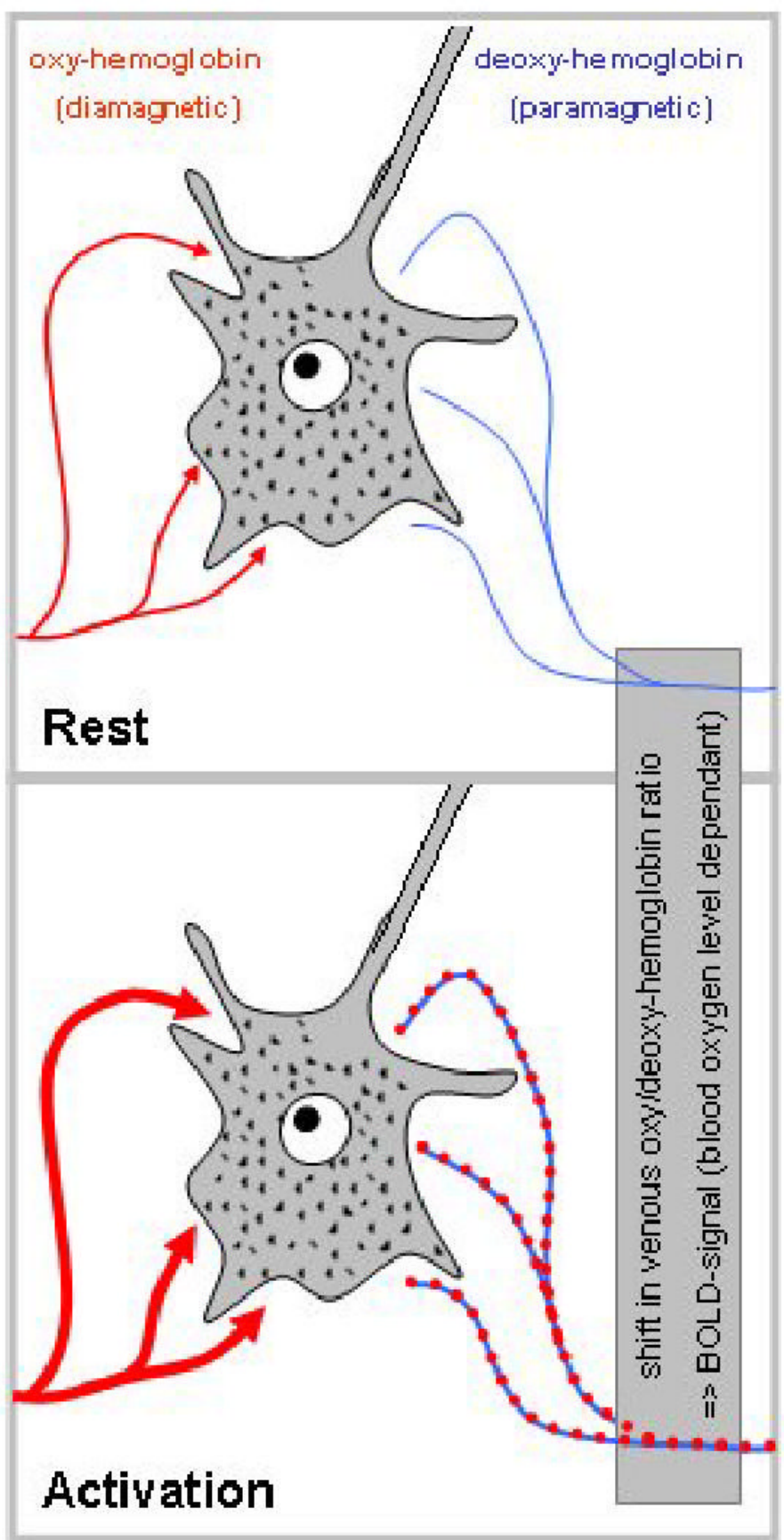

Figure 6.

Brain activation in children doing an active verb generation paradigm (top, $\mathrm{n}=158$ ) or a passive story task (bottom, $\mathrm{n}=156$ ). Note lateralization with the verb generation as opposed to bilateral activation in the listening task. 


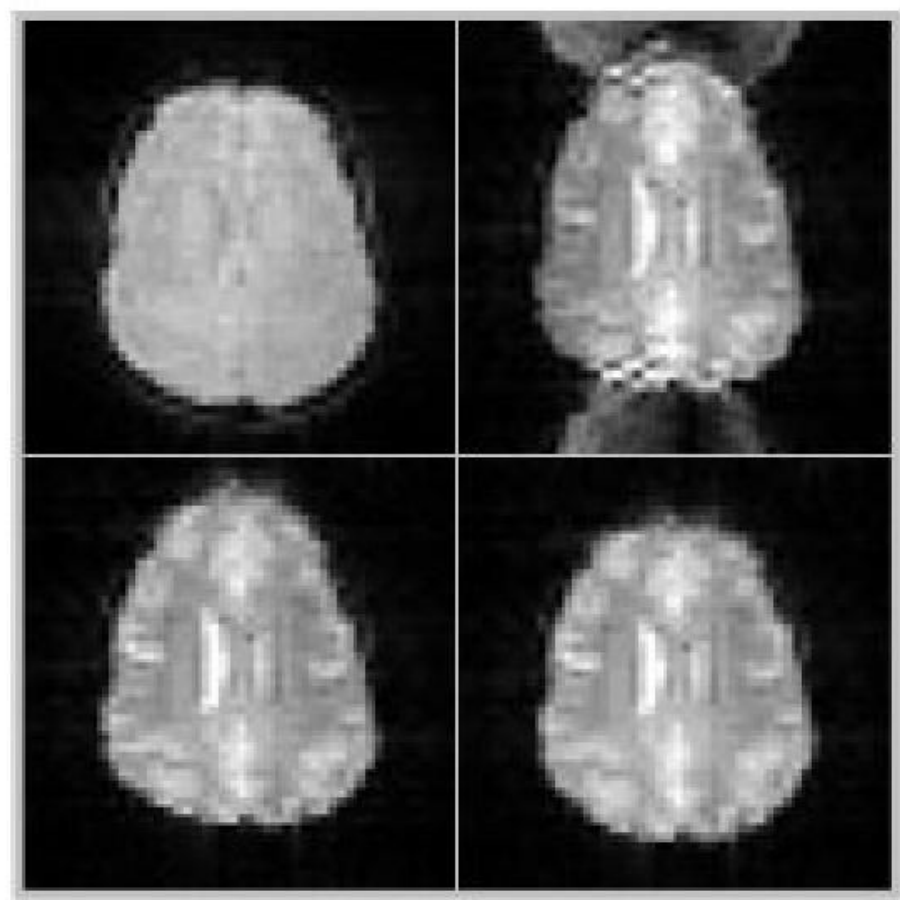

Figure 7.

Cortical lesion as demonstrated on the 3D-rendering of a high-resolution T1-dataset (left, arrow). Note location of the lesion within the primary motor cortex. Right: brain activation while doing a finger-tapping task. Note motor activation both anterior and posterior to the lesion (arrows) and slight posterior dislocation of motor activation due to the lesion's mass effect. 


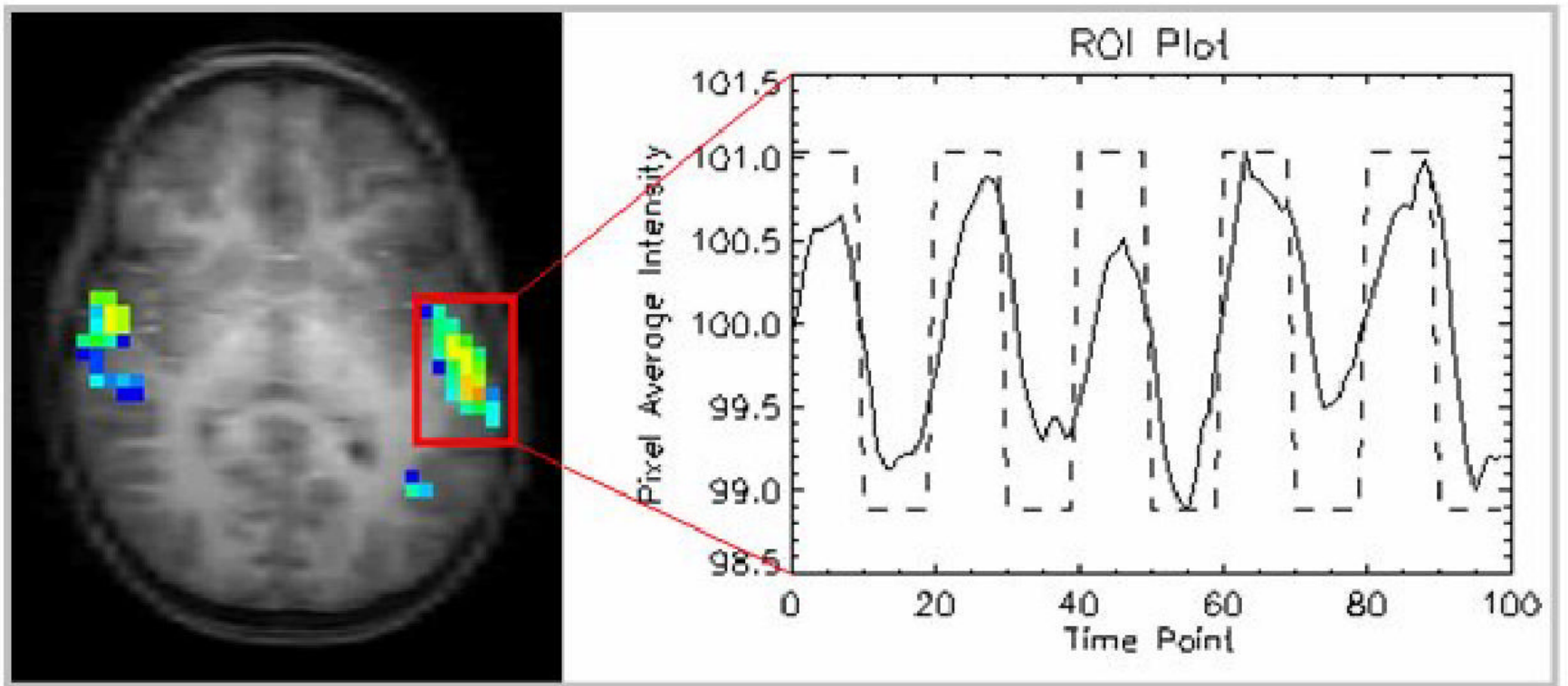

Figure 8.

Detection of false-positive "activation" close to a cortical lesion (left, arrows), corresponding to a pathological vessel as shown by contrast-enhancement (right, arrows). 


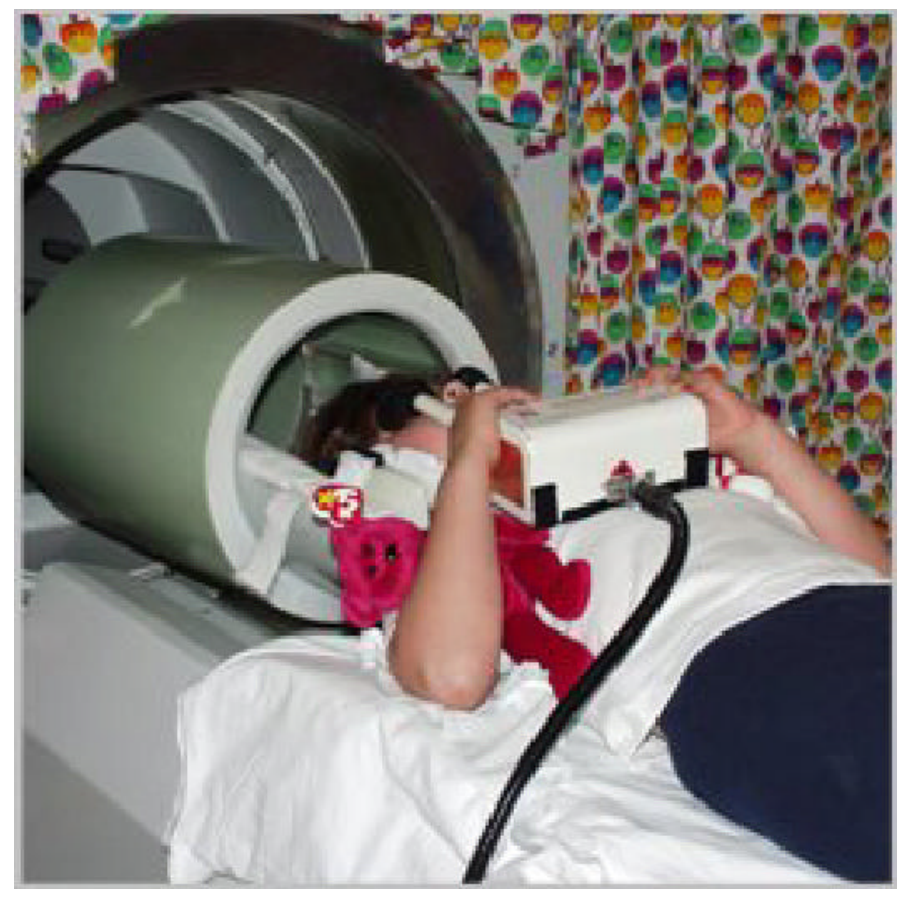

Figure 9.

Hippocampal activation induced by a memory recall paradigm and detected by high-resolution fMRI: bilateral activation in a healthy volunteer (left, arrows), compared to unilateral activation (left only) in a patient with right-temporal lobe epilepsy (right, arrow; result consistent with memory lateralization as detected by Wada-testing). Image courtesy of Dr. Jerzy P. Szaflarski, $\mathrm{MD}, \mathrm{PhD}$, University of Cincinnati [56]. 